\title{
Article
}

\section{Views of medical students: what, when and how do they want statistics taught?}

Fielding, S, Poobalan, A, Prescott, Gordon, Marais, D and Aucott, L Available at http://clok.uclan.ac.uk/25060/

Fielding, S, Poobalan, A, Prescott, Gordon ORCID: 0000-0002-9156-2361, Marais, D and Aucott, $L$ (2015) Views of medical students: what, when and how do they want statistics taught? Scottish Medical Journal, 60 (4). pp. 164169. ISSN 0036-9330

It is advisable to refer to the publisher's version if you intend to cite from the work. http://dx.doi.org/10.1177/0036933015608329

For more information about UCLan's research in this area go to http://www.uclan.ac.uk/researchgroups/ and search for < name of research Group>.

For information about Research generally at UCLan please go to http://www.uclan.ac.uk/research/

All outputs in CLoK are protected by Intellectual Property Rights law, including Copyright law. Copyright, IPR and Moral Rights for the works on this site are retained by the individual authors and/or other copyright owners. Terms and conditions for use of this material are defined in the policies page.

\section{CLoK}

Central Lancashire online Knowledge www.clok.uclan.ac.uk

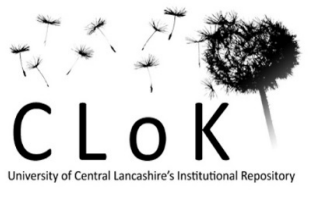


Views of medical students: what, when and how do they want statistics taught?

S Fielding ${ }^{1}$, A Poobalan², GJ Prescott ${ }^{1}$, D Marais ${ }^{2}$, L Aucott ${ }^{1}$

${ }^{1}$ Medical Statistics Team, Division of Applied Health Sciences, University of Aberdeen

${ }^{2}$ Postgraduate Education Group, Division of Applied Health Sciences, University of Aberdeen

Corresponding author

Dr Shona Fielding

Lecturer in Medical Statistics, Medical Statistics Team

Division of Applied Health Sciences, University of Aberdeen

Polwarth Building, Foresterhill, Aberdeen

AB25 2ZD

Tel: 01224437107

Email: s.fielding@abdn.ac.uk

Words: 2629 


\section{Abstract}

\section{Background}

A key skill for a practicing clinician is being able to do research and understand the statistical analyses and interpret results in the medical literature. Basic statistics has become essential within medical education, but when, what and in which format is uncertain.

\section{Methods}

To inform curriculum design/development we undertook a quantitative survey of fifth year medical students and followed them up with a series of focus groups to obtain their opinions as to what statistics teaching they want, when and how.

\section{Results}

145 students undertook the survey and five focus groups were held with between 3 to 9 participants each. Previous statistical training varied and students recognised their knowledge was inadequate and keen to see additional training implemented. Students were aware of the importance of statistics to their future careers, but apprehensive about learning. Face-to-face teaching supported by 
online resources was popular. Focus groups indicated the need for statistical training early in their degree and highlighted their lack of confidence and inconsistencies in support.

\section{Conclusion}

The study found that the students see the importance of statistics training in the medical curriculum but that timing and mode of delivery are key. The findings have informed the design of a new course to be implemented in the third undergraduate year. Teaching will be based around published studies aiming to equip students with the basics required with additional resources available through a virtual learning environment.

Key words: statistics, medical education, curriculum 


\section{Introduction}

A fundamental component for practicing clinicians is reviewing the evidence and making informed choices about suitable treatment for patients. Understanding statistical analyses and accurate interpretation of results is key to efficient clinical practice, and this is recognised by the General Medical Council (GMC) (1). However, these recommendations come with no direction into content and volume of teaching required. As such, statistics teaching varies among UK medical schools.

Despite this recognition, very few previous studies have explored this issue. Miles et al surveyed practicing doctors on their views of undergraduate statistical training and the need for the skills in daily practice (2). They showed clinicians prefer teaching based around examples of statistical methods used within clinical practice rather than the theory. Postgraduate medical students agreed with the importance of statistical training, but found it difficult, were often unsure of the meaning of statistical terms and struggled with appropriate method choice (3). Nearly one-third of their subjects indicated a lack of statistics training in their career and suggested more effective training within undergraduate education. A recent study assessing the attitudes of graduate 
medical students found that even those with numerical backgrounds were still apprehensive and perceived statistics as difficult (4).

At the University of Aberdeen no formal statistical training exists within the undergraduate medical curriculum and students have had varied statistical experience through student selected modules, electives (small research project) and informal daily drop-in student statistics clinic. Some students undertake a full basic statistics course within the intercalated BSc Medical Science (BMedSci) degree. This course covers basic descriptive statistics, univariate tests (e.g. chi-squared tests, independent t-tests, ANOVA) and an introduction to linear regression.

This mixed methods study aimed to explore the statistical wants and needs of current undergraduates medical students. The results, in combination with previous studies (2-5), will inform the design and delivery of an appropriate statistical course for a large cohort of undergraduate medical students.

\section{Methods}

We undertook a concurrent mixed methods study with fifth year medical students at the University of Aberdeen (UoA). Given the varied experience, 
adequate exposure to various clinical situations and potential appreciation of the need for evidence based medicine, fifth year students were deemed ideal to approach to gain opinions about what would be useful, when and in what format.

The study consisted of a quantitative survey and series of focus group discussions (FGD). The latter aimed to obtain an extended understanding of the experiences and perceptions of medical students about statistical teaching received and to identify relevant factors that will contribute to developing statistical teaching. Ethical approval was provided by College Ethics Review Board, UoA.

\section{Data Collection}

The full cohort of 153 fifth year medical students were targeted (academic year 2013/14). The survey was introduced and conducted in a timetabled session of each general practice rotation. With the author's permission our survey was developed from a previously used survey for practicing clinicians $(2,6)$. The questionnaire asked basic demographic information; components students had undertaken in their degree (e.g. clinical contact, numerical analysis) and how relevant they thought medical statistics was within each; when they had been 
exposed to statistics; in what format and whether it was perceived as relevant. For the elective project, students were asked about their statistical knowledge, whether they struggled and whether they had sought help in planning and analysis. Students were asked about sources of help as well as their opinions on the format and timing of future teaching.

During the survey session, the purpose of the FGD was explained and information leaflets provided and students invited to attend. On the day, written consent was obtained, the process of the FGD was explained and participants were under no obligation to participate and free to leave at any time. A topic guide was used to facilitate the discussions with at least two researchers present at each FGD.

\section{Data Analysis}

Using IBM SPSS Statistics version 21 (7) all questionnaire variables were appropriately summarised. Appropriate Chi-squared tests (Pearson X², continuity correction or Fishers exact test) were used to compare students who completed the BMedSci versus those who had not and secondly between those who had already completed their elective rotation and those who had not. All 
FGD were recorded, transcribed verbatim and analysed using 'Thematic Analysis'. All data were coded for the group and day but otherwise anonymised.

\section{Results - Survey}

The response rate was $94.7 \%$ (145/153). The median (inter-quartile range) age was $23(22,24)$ years. Just over half were female $(n=79,55 \%)$, with $76 \%$ of British nationality $(n=110), 10(7 \%)$ other European and $24(17 \%)$ other nationalities. About a fifth had completed the BMedSci degree (22\%).

The majority of students felt statistics was very/extremely relevant to each component, except 'clinical contact' where they felt statistics had relevance but less so (Table 1). Most students $(74.8 \%)$ had read research articles and $59.4 \%$ had undertaken some analysis. Table 2 describes the information on previous statistical training. No statistical teaching was indicated by $16 \%$ of students with most $(68 \%)$ indicating they had received between one and three sessions. For timing of previous statistics training, most cited their third year within the community course $(61 \%)$, with about $40 \%$ at school and about a fifth during the BMedSci.. Students recalled previous teaching was lecture-based or small group tutorials. Teaching was thought to be somewhat/very relevant at the time 
by $57 \%$ of students . The existence of the student statistical clinic was known by $62 \%$, but only $23 \%$ had used the service.

Small group tutorials, practical sessions and drop-in sessions were identified as being most helpful, with large lectures less preferred (Table 3). When students were asked directly whether training should be delivered entirely online (virtual learning environment) only 39 (27.1\%) agreed. There was no consensus on the exact timing of future teaching with the third year preferred by $60.7 \%$ but the fourth and fifth years also being identified (57.9\% each). Many students thought medical statistics should be core, but not examined (59\%), while 32\% thought it should be optional.

Statistical knowledge was felt to be inadequate for elective projects by $33 \%$ with more than $40 \%$ saying their knowledge (negatively) influenced their choice of project (Table 4$)$. The majority of students $(78 \%)$ struggled (a little or a lot) with statistical aspects, only 19 (13.4\%) sought help at the statistical clinic for planning, but $43.6 \%$ with analyses (Table 4). Other than the student clinic, the main sources of help reported by students for their elective projects were 
supervisors (48\%), Google (57\%), books (26\%), YouTube $(15 \%)$ and, other students $(22 \%)$.

Receipt of a greater number of previous sessions was associated with the students who had done the BMedSci $(p<0.001)$ (Table 4). Their use of the statistical consultancy service was also significantly higher compared to the non-BMedSci students $(56.2 \%$ vs. $12.5 \%, \mathrm{p}<0.001)$. A greater proportion of the BMedSci students felt their statistical knowledge was adequate for the elective and fewer of them struggled with statistical aspects of the elective. No differences were found in terms of seeking help for planning or analysing their data, and while a greater proportion of the non-BMedSci students said their statistical knowledge influenced their choice of project, the difference was not significant.

Due to the rotation system in fifth year, some of our respondents had not undertaken their elective project, $n=47(32 \%)$. There was no statistical difference in the proportion of the post-elective students who had used the student clinic $(26.5 \%)$ compared to those who were pre-elective $(14.5 \%), p=$ 0.271. Having completed their elective, $21.4 \%$ felt their statistical knowledge was adequate, but only $10.9 \%$ felt it was going to be adequate before 
embarking on their elective $(p=0.199)$. A higher proportion of the pre-elective students felt they would struggle a lot with statistical aspects of their elective, $37.0 \%$, compared to $28.9 \%$ of those who had done the elective and struggled ( $p$ $=0.210)$. There were no differences between groups for students visiting the clinic when planning the elective $(p=0.625)$ with $13.4 \%$ doing so. Only $9 \%$ of those pre-elective thought they would not seek help at the clinic for analysis, but around half (47.8\%) thought they would seek a lot. This compares to $79.2 \%$ of those having completed the elective not seeking help and only $8.3 \%$ seeking a lot of help $(p<0.001)$.

\section{Results - FGD}

In total, five FGD (36 participants) were conducted with each FGD ranging from three to nine. Four main themes emerged: the need for statistical training in the medical curriculum; lack of confidence; inconsistencies in support and expectations for career. Within each of these themes, several sub-themes were identified as presented in Table 5 alongside relevant quotes from students.

Theme 1: Need for statistical training in medical curriculum Most participants indicated a need for basic statistical training within the medical curriculum. They felt/expressed an initial reluctance to learn statistics but that it 
should be incorporated into the curriculum and made compulsory. There was a discussion about the subject knowledge versus technical and interpretative skills. For example, some were able to undertake a specific calculation, but lacked the theoretical background and skills to interpret them. Some, however, were able to interpret results but had no knowledge to handle and analyse primary data.

Timing of statistical training was an important sub-theme. Students felt the importance of statistics and its application should be emphasised earlier (third year) with the basics statistics taught. This should then be built on and followed up in the fifth year as a refresher course as fourth year was not suitable. This suggestion came with the caveat that very 'early' teaching might not be well attended.

Mode of delivery was thought to be important. It was felt that basics should be taught face-to-face, preferably in small groups allowing for interaction and explanation, followed up with on-line material and/or teaching workbooks.

Preparation for elective projects was felt to be inconsistent as whilst all students submit their elective proposals at the same time, they are conducted at 
different times. This can lead to a long time lag between planning and conducting projects. Students felt that basic statistical knowledge would help in planning project proposals.

\section{Theme 2: Lack of confidence}

The majority of students expressed a lack of confidence in statistics. Diversity in their backgrounds and lack of previous knowledge/experience contributed to the uncertainty and their need for basic training (theme 1). Students reported letting their uncertainty about statistics influence their elective choice, with some selecting non-numeric projects due to the lack of confidence in handling data.

\section{Theme 3: Inconsistencies in support during medical training}

The existence of the statistics clinic was not known by many students. While students appreciated this support, some felt that there was not enough time to discuss issues and problems with continuity, as different staff members were available each day. Students felt a huge amount of uncertainty around elective projects and were unprepared for the methodology of their research projects. Students seem to get variable levels of support from elective supervisors, depending on the supervisor's statistical knowledge and expertise. 
Theme 4: Expectations for career

Participants realised the need to learn statistics early in their medical training. They felt the importance of learning statistics was not emphasised enough in their earlier days of training, and it was not until experiencing the pressures of electives that this was realised. Most felt that they would need to get involved in research at some point in their career and that statistics would help them with this. Discussion

The key findings were that there was no obvious consensus on timing of teaching but third year had some advantages. Students preferred small group teaching, were not keen on statistics being examinable, but recognised the need for it to be core to ensure engagement. The format prompted much discussion in the FGD, with students seeing the value of online material as a resource rather than the main mode of delivery. This went against the expectation of the research team, who thought in this digital age, online learning with flexible access would be popular with students.

It was acknowledged that students who had undertaken the BMedSci were at an advantage later in their medical degree and future career. Students felt the importance of statistics to medicine should be stressed much earlier and not on graduating medical school. Very few students sought help in the planning stage 
of their elective projects a finding echoed by a study in India which found only $31.3 \%$ of final year postgraduate medical students sought help in planning (3).

Two medical students from the University of Bristol expressed the opinion that statistical teaching should come as early as possible but with reinforcement thereafter perhaps through the use of an online resource (8). However they also recognised that if too early in the degree students might not see the relevance, a sentiment echoed in the present study. Students indicated that they knew statistics was important for their careers but that this knowledge was obtained recently and not as an early-year undergraduate. Swift et al found that student perceptions about what was important for careers were consistent with GMC recommendations $(1,6)$, namely being able to critically appraise published research, perform clinical audit and better understand risk to explain it to patients. In this study, the majority of students recognised the relevance of statistics to these components.

Hannigan et al recommends that any initial statistical teaching with medical students should focus on the misconception that previous mathematical performance has a relationship with statistical ability (4). Reducing this anxiety will encourage students to engage with statistics teaching. This anxiety was 
evident, with students expressing a lack of confidence in their statistical ability and an avoidance of statistics if possible. As a consequence, it is suggested that a statistical glossary is linked to the clinical lectures from the first year, where students will be signposted to statistical terms and additional resources to aid explanation. It is hoped that this light touch approach will allow them to gain confidence with basic statistical concepts used in their everyday practice before any formal statistical teaching is undertaken.

Freeman et al assessed student performance after two different methods of teaching, one being a standard lecture style theoretical course and another centered around using concepts and examples from the literature utilising a variety of teaching methods and media (5). The latter proved to be successful, and is corroborated by this study with students indicating that they want some element of face-to-face teaching in smaller groups, followed by a resource (online or paper-based) that is continuously available. So in addition to the provision of statistical terminology early on in the medical curriculum, a short face-to-face course incorporating varying teaching styles and activities is suggested to run at the end of their third year. During this course, terminology used in recent literature will be identified, expanded to show relevance and then 
developed into basic statistical concepts without too much theory or numerical analyses.

A strength of this study is that it targeted undergraduate medical students while previous studies have focused on practicing clinicians. Although based in one institution and statistics teaching differs across institutions, our study findings were in line with other studies, but were of particular pertinence to undergraduate medical training.

\section{Conclusion}

This study has provided pertinent views that medical students have about learning statistics, primarily that statistics is important within their medical training, but that timing and mode of delivery are key. As a consequence, a series of elements have been identified as being useful and we are now in the process of developing and implementing an undergraduate statistics course. Some of these may be of interest to other medical schools (UK and elsewhere) and adapted for their particular environment and needs. In the future, we plan to assess the views of students with regard to the success and relevance of these new initiatives, gaining feedback to make improvements. 


\section{Declaration of interest}

The authors report that there are no conflicts of interest. 


\section{References}

1. GMC: Tomorrow's Doctors: Outcomes and standards for undergraduate Medical Education. London: General Medical Council; 2009.

2. Miles S, Price GM, Swift L et al. Statistics teaching in medical school: Opinions of practising doctors. BMC Medical Education 2010; 10:75.

3. Gore AD, Kadam YR, Chavan PV, Dhumale GB. Application of biostatistics in research by teaching faculty and final-year postgraduate students in colleges of modern medicine: A cross-sectional study. Int $J$ Appl Basic Med Res 2012; 2(10): 11-16.

4. Hannigan A, Hegarty AC, McGrath D. Attitudes towards medical students of graduate entry medical students: the role of prior learning experiences. BMC Medical Education 2014; 14:70.

5. Freeman JV, Collier S, Staniforth D, Smith KJ. Innovations in curriculum design: A multi-disciplinary approach to teaching statistics to undergraduate medical students. BMC Medical Education 2008; 8: 28.

6. Swift L, Miles S, Price GM et al. Do doctors need statistics? Doctors' use of and attitudes to probability and statistics. Statistics in Medicine 2009; 28: 1969-1981.

7. IBM Corp. Released 2012. IBM SPSS Statistics for Windows, Version 21.0. Armonk, NY: IBM Corp. 
8. Astin J, Jenkins $Y$, Moore L. Medical students' perspective on the teaching of medical statistics in the undergraduate medical curriculum. Statistics in Medicine 2002; 21: 1003-1006. 


\section{Tables}

Table 1: Components of practice where statistics needed - N (\%)

\begin{tabular}{lcccccc} 
& $\begin{array}{c}\text { Completed } \\
\text { Component }\end{array}$ & $\begin{array}{c}\text { Not } \\
\text { relevant }\end{array}$ & $\begin{array}{c}\text { A little } \\
\text { relevant }\end{array}$ & $\begin{array}{c}\text { Somewhat } \\
\text { relevant }\end{array}$ & $\begin{array}{c}\text { Very } \\
\text { relevant }\end{array}$ & $\begin{array}{c}\text { Extremely } \\
\text { relevant }\end{array}$ \\
\hline Clinical Contact & $139(97.2)$ & $15(10)$ & $30(21)$ & $64(44)$ & $29(20)$ & $6(4)$ \\
Explaining risk & $65(45.5)$ & $2(1)$ & $1(1)$ & $25(18)$ & $72(51)$ & $41(29)$ \\
Interpreting results & $56(39.2)$ & $0(0)$ & $1(1)$ & $21(15)$ & $65(46)$ & $56(39)$ \\
Reading research & $107(74.8)$ & $0(0)$ & $5(4)$ & $24(17)$ & $75(52)$ & $40(28)$ \\
Using research to explore treatments & $58(40.6)$ & $0(0)$ & $1(1)$ & $19(14)$ & $69(49)$ & $52(37)$ \\
Analysing own data & $85(59.4)$ & $0(0)$ & $0(0)$ & $8(6)$ & $43(30)$ & $91(64)$ \\
Audits & $82(57.3)$ & $0(0)$ & $3(2)$ & $15(11)$ & $62(44)$ & $61(43)$ \\
Critical appraisal & $115(80.4)$ & $0(0)$ & $3(2)$ & $21(15)$ & $66(46)$ & $53(37)$ \\
\hline
\end{tabular}


Table 2: Statistical training

\begin{tabular}{|c|c|c|c|}
\hline Previous training ${ }^{1}$ & $\mathbf{N}$ & $\%$ & Rank \\
\hline School & 57 & 39 & 2 \\
\hline Previous degree & 16 & 11 & 7 \\
\hline Medical degree -1 st/2nd year & 23 & 16 & 5 \\
\hline Medical degree - 3rd year community course & 89 & 61 & 1 \\
\hline BSc Medical Sciences (BMedSci) (3 ${ }^{\text {rd }}$ year) & 31 & 21 & 3 \\
\hline Medical degree 4th year & 26 & 18 & 4 \\
\hline Medical degree 5 th year & 17 & 12 & 6 \\
\hline None of the above & 5 & 3 & 9 \\
\hline Cannot remember & 13 & 9 & 8 \\
\hline \multicolumn{4}{|l|}{ Teaching as part of medical degree } \\
\hline None & 22 & 16 & 3 \\
\hline One session (up to 2 hours) & 47 & 33 & 2 \\
\hline 2-3 sessions (up to 2 hours each) & 50 & 35 & 1 \\
\hline 4 or more sessions (over 1 day in total) & 15 & 11 & 4 \\
\hline Equivalent of one week teaching & 8 & 6 & 5 \\
\hline Missing & 3 & - & - \\
\hline \multicolumn{4}{|l|}{ What format did the teaching take ${ }^{1}$} \\
\hline Did not have teaching & 21 & 15 & 3 \\
\hline Lecture & 96 & 67 & 1 \\
\hline SPSS Practical & 20 & 14 & 4 \\
\hline Practical (other software) & 4 & 3 & 7 \\
\hline Online material & 13 & 9 & 5 \\
\hline Small group tutorials & 56 & 39 & 2 \\
\hline Other & 10 & 7 & 6 \\
\hline \multicolumn{4}{|l|}{ Did teaching seem relevant at the time? } \\
\hline Not relevant & 14 & 10 & 4 \\
\hline A little relevant & 26 & 18 & 3 \\
\hline Somewhat relevant & 52 & 36 & 1 \\
\hline Very relevant & 31 & 21 & 2 \\
\hline Extremely relevant & 8 & 6 & 5 \\
\hline Not applicable & 14 & 10 & - \\
\hline \multicolumn{4}{|l|}{ Aware of Medical Statistics Team Support } \\
\hline Yes and I have used the service & 33 & 23 & 3 \\
\hline Yes, but not used the service & 56 & 39 & 1 \\
\hline No & 56 & 39 & 1 \\
\hline
\end{tabular}

1 Percentages do not add to 100 as respondents were asked to tick all that applied. 
Table 3: Future Medical Training - helpful modes of teaching

\begin{tabular}{lcccccc} 
& $\begin{array}{c}\text { Not } \\
\text { helpful }\end{array}$ & $\begin{array}{c}\text { A little } \\
\text { helpful }\end{array}$ & $\begin{array}{c}(\%) \\
\text { Somewhat } \\
\text { helpful }\end{array}$ & $\begin{array}{c}\text { Very } \\
\text { helpful }\end{array}$ & $\begin{array}{c}\text { Extremely } \\
\text { helpful }\end{array}$ & $\begin{array}{c}\text { Rank } \\
\text { very/extrem } \\
\text { helpful }\end{array}$ \\
\hline Lectures (face to face) & $17(12)$ & $33(23)$ & $45(32)$ & $32(22)$ & $16(11)$ & 6 \\
SPSS Practical session & $3(2)$ & $5(4)$ & $27(19)$ & $61(44)$ & $44(31)$ & 2 \\
Small group tutorials & $2(1)$ & $2(1)$ & $23(16)$ & $77(53)$ & $41(28)$ & 1 \\
Online lectures through & $19(13)$ & $22(15)$ & $44(31)$ & $40(28)$ & $18(13)$ & 5 \\
MyMBChB ${ }^{*}, \#$ & $7(5)$ & $15(11)$ & $37(26)$ & $49(35)$ & $34(24)$ & 4 \\
$\begin{array}{l}\text { Designated drop in sessions } \\
\text { Discussion boards through }\end{array}$ & $15(36)$ & $47(34)$ & $28(20)$ & $10(7)$ & $4(3)$ & 7 \\
MyMBChB\# & & & & & & \\
Printed worked examples & $6(4)$ & $13(9)$ & $34(25)$ & $53(38)$ & $32(23)$ & 3 \\
Other & $0(0)$ & $1(50)$ & $0(0)$ & $1(50)$ & $0(0)$ & - \\
\hline
\end{tabular}

* $27 \%$ said entirely online would suit them; $56 \%$ said no and $17 \%$ said maybe.

\# MyMBChB is the virtual learning environment used by medical students at Aberdeen 
Table 4: Comparison of BMedSci students versus non BMedSci (Number and \% down page)

\begin{tabular}{|c|c|c|c|c|}
\hline & All & No BMedSci & BMedSci & p-value \\
\hline Number of Teaching Sessions & & & & $<0.001$ \\
\hline None & $22(16)$ & $17(16)$ & $5(16)$ & \\
\hline 1 session (up to 2 hours) & $47(33)$ & $40(37)$ & $7(22)$ & \\
\hline 2-3 sessions (up to 2 hours each) & $50(36)$ & $45(410)$ & $5(16)$ & \\
\hline 4 or more sessions (over 1 day in total) & $14(10)$ & $5(5)$ & $9(28)$. & \\
\hline Equivalent of one week teaching & $8(6)$ & $2(2)$ & $6(19)$ & \\
\hline Missing & 3 & 3 & - & \\
\hline Use of the student clinic & & & & $<0.001$ \\
\hline Yes and I have used the service & $32(22)$ & $14(13)$ & $18(56)$ & \\
\hline Yes, but I have not used the service & $56(39)$ & $44(39)$ & $12(38)$ & \\
\hline No & $56(39)$ & $54(48)$ & $2(6)$ & \\
\hline $\begin{array}{l}\text { Was your statistical knowledge adequate } \\
\text { for your elective? }\end{array}$ & & & & $<0.001$ \\
\hline Not at all & $47(33)$ & $44(39)$ & $3(10)$ & \\
\hline A little & $70(49)$ & $56(50)$ & $14(45)$ & \\
\hline A lot & $26(18)$ & $12(11)$ & $14(45)$ & \\
\hline $\begin{array}{l}\text { Did you level of statistical knowledge } \\
\text { influence elective choice? }\end{array}$ & & & & 0.151 \\
\hline Not at all & $85(59)$ & $62(55)$ & $23(72)$ & \\
\hline A little & $29(20)$ & $23(21)$ & $6(19)$ & \\
\hline A lot & $30(21)$ & $27(24)$ & $3(9)$ & \\
\hline $\begin{array}{l}\text { Did you struggle with statistical aspects of } \\
\text { your elective? }\end{array}$ & & & & $<0.001$ \\
\hline Not at all & $31(22)$ & $17(16)$ & $14(44)$ & \\
\hline A little & $67(47)$ & $51(46)$ & $16(50.0)$ & \\
\hline A lot & $44(31)$ & $42(38)$ & $2(6)$ & \\
\hline $\begin{array}{l}\text { Did you seek help at the student clinic in } \\
\text { planning your elective? }\end{array}$ & & & & 0.625 \\
\hline Not at all & $122(87)$ & $94(86)$ & $28(90)$ & \\
\hline A little & $15(11)$ & $13(12)$ & $2(7)$ & \\
\hline A lot & $3(2)$ & $2(2)$ & $1(3)$ & \\
\hline $\begin{array}{l}\text { Did you seek help at the student clinic in } \\
\text { analysing your elective? }\end{array}$ & & & & 0.143 \\
\hline Not at all & $80(57)$ & $63(56)$ & $17(53)$ & \\
\hline A little & $32(23)$ & $21(19)$ & $11(34)$ & \\
\hline A lot & $29(21)$ & $25(23)$ & $4(13)$ & \\
\hline
\end{tabular}


Table 5: Statistical teaching during medical training: themes and sub themes

\begin{tabular}{|c|c|}
\hline Subthemes & Quotes \\
\hline \multicolumn{2}{|c|}{ Theme 1: Need for statistical training in medical curriculum } \\
\hline Level of training & $\begin{array}{l}\text { D1.G1: "I don't think you have to be actual experts when you come out but I think it's important that for } \\
\text { yourself you're not actually terrified of the word "statistics". } \\
\text { D2.G1: "I think from the understanding papers point of view, we're so evidence-led now, or supposed } \\
\text { to be, I think there's definitely a point to make understanding statistics compulsory, whether you then } \\
\text { push to make people do statistics is almost a different issue in some ways" } \\
\text { D3.G1: "it's good for when you read a systematic review or research articles so you can realise what } \\
\text { the definitions mean but we've got no teaching on how that actually get your own data and put it into a } \\
\text { programme and work out from there." }\end{array}$ \\
\hline Timing of training & $\begin{array}{l}\text { D3.G2: "I think third year would be a good time to cover a good chunk of the theory and then in fifth } \\
\text { year you could have a recap session just to remind you that you need to know about this for your } \\
\text { elective. But in third year I think you need to cover it (inaudible) time probably. } \\
\text { D1.G1: "because fourth year nobody's going to be interested because the final's coming up and the } \\
\text { fifth year's probably well, somewhere in fifth year would be beneficial as well but by then it's too } \\
\text { (inaudible), by then it's too late to start...........Any time but fourth year." }\end{array}$ \\
\hline
\end{tabular}




\begin{tabular}{|c|c|}
\hline & $\begin{array}{l}\text { D1.G2: "if we had the... just a little bit as we go along, not a lot, because people won't enjoy it or } \\
\text { engage in it. If it's a little bit every now and then, as you're progressing through, it definitely would have } \\
\text { helped me" }\end{array}$ \\
\hline Mode of delivery & $\begin{array}{l}\text { D3.G2: "I think you would need to have a lecture or a couple of lectures to cover all of the basic } \\
\text { concepts but as much as the general basic concepts as you expect a graduate of medicine to know } \\
\text { before you could then do a couple of computer based tutorials or something working through some } \\
\text { statistical happenings." } \\
\text { D1.G1: "Personally I think it would be beneficial if it's like small group teaching ....then you can ask } \\
\text { questions if you don't understand something. If it's online and you don't understand something, then to } \\
\text { move onto the next step it's like impossible because you don't understand the first part of it." }\end{array}$ \\
\hline Elective preparation & $\begin{array}{l}\text { D2.G1: "The other issue is that we plan for our elective a year before it happens and for me, I wasn't } \\
\text { very confident in my statistics.....So when you say pre-elective, you're not just talking about it before } \\
\text { you go away to do it, you're talking about almost before you plan it." } \\
\text { D2.G1: "But with all the electives you go through a planning process and you have to submit a } \\
\text { proposal. Whether there was maybe an adjunct to that where you had to submit a statistical proposal } \\
\text { as well and get an idea of how much statistics was involved and whether it was achievable. Like when } \\
\text { you submit a proposal you have to submit whether it will require ethnical approval, so almost if there } \\
\text { was statistical approval for it as well, that might be the time to.." (some students in the group } \\
\text { thought it would be too much work) }\end{array}$ \\
\hline \multicolumn{2}{|l|}{ Theme 2: Lack of confidence } \\
\hline Uncertainty and diversity in background & $\begin{array}{l}\text { D1.G2: "No, I think every time l've attempted it I just don't understand it and l've never really had any } \\
\text { formal teaching on it or anything like it" }\end{array}$ \\
\hline
\end{tabular}




\begin{tabular}{|c|c|}
\hline & $\begin{array}{l}\text { D1.G2: "I don't know, just because from my background I hate maths in general, and for my GCSE I } \\
\text { had to have a tutor, and things like that. I did find it very difficult and I still do. So giving you the basics, } \\
\text { real basics" }\end{array}$ \\
\hline Influence on elective choice & $\begin{array}{l}\text { D1.G1: "I don't know how good I will be at the statistics so I don't want to put a negative thing on myself } \\
\text { by trying to deal with the stats and I don't understand it completely..... I definitely picked a project that's } \\
\text { not as statistical based ...because I didn't want to." } \\
\text { D3. G1: "Literally, I chose my elective, well, I organised my elective project deliberately not to involve } \\
\text { stats because I had no idea." }\end{array}$ \\
\hline \multicolumn{2}{|c|}{ Theme 3: Inconsistencies in support during Medical training } \\
\hline Statistics clinic support & $\begin{array}{l}\text { D1.G1: "we met the statisticians in the team who said that they ran an hour session between lunchtime } \\
\text { otherwise we'd never hear about that. We had no idea that there's just drop in sessions that you can } \\
\text { just go to for anything." } \\
\text { D1.G1: "...it was only an hour and there were a couple of people waiting there and it was a bit difficult } \\
\text { to get time with somebody....because I went a couple of times and it was always a different person } \\
\text { each time. I had to kind of explain the whole project over again to the person. I got some different } \\
\text { suggestions from -- it probably didn't help me to -- I think having gone to the clinic helped me put things } \\
\text { in perspective. }\end{array}$ \\
\hline Experience during tutorials and electives & $\begin{array}{l}\text { D1.G1: "because you don't know what's going to happen, you go out there, you might have to change } \\
\text { entirely. So in an ideal world you'd know what you're doing about a month before and then go to a }\end{array}$ \\
\hline
\end{tabular}




\begin{tabular}{|c|l|}
\hline \multicolumn{1}{|c|}{} & $\begin{array}{l}\text { clinic and like, this is what l'll be doing, what do you think's best and you have a plan but in reality, it's a } \\
\text { little more difficult." } \\
\text { D1.G2: "I've got to sort everything else out like ethical approval and I've still got to do all of that, l'm just } \\
\text { not organised enough to do, planning your flights, getting your insurance and the statistics you leave } \\
\text { until the end. Like your project is when you're there, everything else is getting there." } \\
\text { D3.G1: "You've no idea so then some of them go and do regression models and other people are just } \\
\text { adding it up on a piece of paper and a calculator. " }\end{array}$ \\
\hline Level of supervisor/tutor experience & $\begin{array}{l}\text { D2.G1: "I think yeah, my supervisor was a bit unsure about statistics himself, so he kind of directed } \\
\text { me...to Google" } \\
\text { D2.G1: "there was a statistician that could have helped me but then again, he was Japanese, so to do } \\
\text { statistics in another language would also have been a bit tricky." } \\
\text { D3.G1: "Yeah. On the supervisor thing, with your supervisors you approach them and they have } \\
\text { completely different levels of -- some people might be heavily involved in research and they're also } \\
\text { getting to be there as a sort of if you're in trouble" }\end{array}$ \\
\hline Theme 4: Expectations for career & $\begin{array}{l}\text { D2.G1: "I, probably in the first year, I didn't see the importance of stats......It didn't seem very relevant } \\
\text { to me, ...but yeah, probably if at the very start of the uni or whoever had said that stats is important, it's } \\
\text { compulsory and you do it in the first year, then it probably made me realise how important it is and then } \\
\text { I would be more accepting to it as well." }\end{array}$ \\
\hline Understanding the importance &
\end{tabular}




\begin{tabular}{|l|l|}
\hline $\begin{array}{l}\text { D3.G1: "But I don't think the relevance of doing critical appraisals and doing research in general is } \\
\text { really made obvious. Personally I wasn't aware of how relevant it would be later on in your career and } \\
\text { you can't hide from it, it's always going to be there now like audits and things." } \\
\text { D3.G2: "I think what would be important if they were to bring it in in third year is you'd have to at the } \\
\text { start of the course say, "It's going to be a slog, it's going to be hard work but this is why we're doing it } \\
\text { and this is why we need it" and hopefully if that was put across in a way that was approachable and } \\
\text { was sensible then hopefully people would interact with it." }\end{array}$ \\
\hline Expectations from a medical doctor & $\begin{array}{l}\text { D3.G2: "even if you're a GP and you're looking up which medicine would be the best to give the patient } \\
\text { you're looking up recent increments then it would be helpful to know (inaudible) and P values and all } \\
\text { that kind of stuff. " } \\
\text { D3.G2:" basically all the specialist programmes to get into now you need to have done your own } \\
\text { research and going in and doing audits and even just if you want to say do a (inaudible) programme or } \\
\text { something like that you're expected to do audits, you're expected to be involved in primary research" } \\
\text { D2.G1: "Yeah, in the future, if you are presented with projects where you won't shy away or you won't } \\
\text { be intimidated by it if you've had some experience of statistics." }\end{array}$ \\
\hline
\end{tabular}

